\title{
Title: Efficacy of the Addition of Intrathecal Fentanyl to Spinal Anesthesia for Uterine Exteriorization during Caesarean Delivery
}

\author{
Authors: $\quad$ Albie J Malan MBChB*, David C. Campbell MD, MSC, FRCPC*; \\ Jocelyn Martel FRCSC, FACOG\#; Sandy Biem FRCSC, FACOG\# \\ Affiliation: Departments of Anesthesia* and Obstetrics and Gynecology\# \\ Royal University Hospital, College of Medicine, University of Saskatchewan, \\ 103 Hospital Drive, Saskatoon, SK, S7N 0W8
}

INTRODUCTION: One of the most uncomfortable times during cesarean delivery (C-D), under spinal anesthesia (SA), occurs with uterine exteriorization, often predicated by the requirement for improved surgical exposure due to a lateral tear of the uterine incision. Although the addition of intrathecal (IT) fentanyl has been associated with improved SA for routine C-D (1), only 3 studies specifically report its impact on exteriorization. Unfortunately, these studies either lacked sufficient power (2), administered IV fentanyl to the control group (3) or did not report sample size (4) to definitively determine the effect of IT fentanyl. The purpose of this prospective, double-blind, RCT was to determine the effect of the addition of IT fentanyl on maternal response to uterine exteriorization during C-D under SA.

METHODS: Following IRB approval and informed written consent, 40 women scheduled to undergo SA for elective C-D were randomized to receive either Fent ( $=20): 1.4 \mathrm{ml} 0.75 \%$ hyperbaric bupivacaine, $150 \mathrm{mcg}(0.3 \mathrm{ml})$ preservative-free $(\mathrm{PF})$ morphine plus $10 \mathrm{mcg}(0.2 \mathrm{ml})$ of Fentanyl or NS $(\mathrm{N}=20)$ : $1.4 \mathrm{ml} 0.75 \%$ hyperbaric bupivacaine, $150 \mathrm{mcg}(0.3 \mathrm{ml}) \mathrm{PF}$ morphine plus $0.2 \mathrm{ml}$ of $0.9 \%$ saline. VAS $(0-100 \mathrm{~mm})$ for Pain (VASP) was assessed Preoperatively, at Incision, Uterine Exteriorization, Uterine Replacement and PARR. Nausea, vomiting, pruritus, RR and Sp02 were simultaneously evaluated. Neonatal APGAR's and cord ABG's were assessed. VAS $(0-100 \mathrm{~mm})$ maternal satisfaction was recorded in PARR. Any supplementary intraoperative analgesia was limited to IV fentanyl. Data analysis included 2-tailed unpaired T-Test, Chi Square and Fisher's Exact Probability Test with $\mathrm{P}<0.05$ considered significant.

RESULTS: There were no statistical differences in demographics, neonatal birth weight, APGAR's, cord $\mathrm{pH}<7.2$, time between SA and exteriorization, and pruritus (NS: 5\% (1/20); Fent: $15 \%$ $(3 / 20)$ ).VASP scores were 0/100 in both groups at Pre-op, Incision and PARR. No IV Fentanyl was administered. VASP was significantly higher in the NS group at Exteriorization (NS: $14.5 \pm 13.3$ vs Fent: $0 \pm 0, \mathrm{P}<0.001)$ and Replacement (NS: $16.7 \pm 16.7$ vs Fent: $0 \pm 0, \mathrm{P}<0.001)$. Nausea was reported by $30 \%(6 / 20)$ at Exteriorization and 65\% (13/20) at Replacement and Vomiting 5\% (1/20) at Exteriorization and 30\% (6/20) at Replacement in NS compared to 0\% (0/20) for both outcomes at each uterine manipulation in Fent $(\mathrm{P}<0.01)$. Maternal satisfaction was significantly higher in Fent: $99.1 \pm 2.8$ vs NS: $93.6 \pm 6.7(\mathrm{P}<0.003)$.

DISCUSSION: The results of this investigation indicate that uterine exteriorization and replacement during C-D are both associated with significant nausea, vomiting and discomfort all of which are eliminated by the addition of $10 \mathrm{mcg}$ of IT fentanyl to SA, with no adverse maternal or neonatal effects.

REFERENCES: $\quad$ 1. Anesthesiology 91:1919-27, 1999; 2. Acta Anaesth Scand 41:332-8, 1997;

3. Anesth Analg 95:209-13, 2002; 4. Anesth Analg 78:918-20, 1994 